\title{
Potyviral 6K2 Protein Long-Distance Movement and Symptom-Induction Functions Are Independent and Host-Specific
}

\author{
Carl Spetz, ${ }^{1}$ and Jari P. T. Valkonen ${ }^{1,2}$ \\ ${ }^{1}$ Department of Plant Biology and Forest Genetics, Genetics Centre, SLU, PO Box 7080, SE-750 07 Uppsala, Sweden; \\ ${ }^{2}$ Department of Applied Biology, PO Box 27, FIN-00014 University of Helsinki, Finland
}

Submitted 17 September 2003. Accepted 22 December 2003.

\begin{abstract}
Deletion of various portions, or insertion of six histidine residues $(6 \times \mathrm{His})$ into various positions of the membranebound $6 \mathrm{~K} 2$ protein (53 amino acids) of Potato virus $A$ (PVA, genus Potyvirus), inhibited systemic infection in Nicotiana tabacum and N. benthamiana plants. However, a spontaneous mutation (Gly2Cys) that occurred in $6 \mathrm{~K} 2$ adjacent to the $6 \times$ His insert placed between Ser1 and Gly2 enabled systemic infection in a single $N$. benthamiana plant. No symptoms were observed, but virus titers were similar to the symptom-inducing wild-type (wt) PVA. $N$. tabacum plants were not systemically infected, albeit virus propagation was observed in inoculated protoplasts. The $6 \times$ His/Gly2Cys mutant was reconstructed in vitro and serially propagated by mechanical inoculation in $N$. benthamiana. Following the third passage, a novel viral mutant appeared, lacking the last four His residues of the insert, as well as the Gly2 and Thr3 of $6 \mathrm{~K} 2$. It infected $N$. tabacum plants systemically, and in the systemically infected $N$. benthamiana leaves, vein chlorosis and mild yellowing symptoms were observed, typical of wt PVA infection. The mutant virus accumulated to titers similar to wt PVA in both hosts. These results show that the PVA $6 \mathrm{~K} 2$ protein affects viral long-distance movement and symptom induction independently and in a host-specific manner.
\end{abstract}

Potyviruses (genus Potyvirus, family Potyviridae) comprise the largest group (approximately 30\%) of plant-infecting viruses. Many potyviruses are economically harmful, due to the diseases and subsequent yield loss they cause in cultivated plants (Shukla et al. 1994). While the mechanisms of disease induction by potyviruses have remained largely unknown, many regions of the potyviral genome (Fig. 1) have been implicated as determinants of symptom induction in specific virushost combinations. For example, the helper component proteinase (HC-Pro)-encoding region affects vein clearing symptoms observed in tobacco plants (Nicotiana tabacum) infected with Tobacco vein mottling virus (TVMV) (Atreya et al. 1992). The region encoding the C-proximal part of the P3 protein and the $6 \mathrm{~K} 1$ protein of Plum pox virus (PPV) affects the severity of chlorotic mottle symptoms in leaves of Nicotiana benthamiana (Sáenz et al. 2000). The P3- and CI-6K2-VPgencompassing regions of Tobacco etch virus (TEV) contain determinants for the wilting response in tabasco pepper ( $\mathrm{Cap}$ sicum annuum) (Chu et al. 1997). The genomic segment

Corresponding author: J. Valkonen; Telephone: +46 1867 3372; Fax: +46 1867 3392; E-mail: jari.valkonen@vbsg.slu.se encoding the NIa and NIb proteins of Pea seedborne mosaic virus is associated with the vein-clearing symptoms induced in pea plants (Pisum sativum) (Johansen et al. 1996). The Nproximal part of the coat protein $(\mathrm{CP})$ encoding region in $\mathrm{Zuc}$ chini yellow mosaic virus induces veinal chlorosis symptoms in cucumber leaves (Cucumis sativus) (Ullah and Grumet 2002). Also, the noncoding regions may play a role in symptom induction. The $5^{\prime}$ nontranslated region $\left(5^{\prime}-\mathrm{NTR}\right)$ of PPV is involved in induction of chlorotic mosaic symptoms in $N$. clevelandii leaves (Simón-Buela et al. 1997), whereas the 3'NTR of TVMV affects vein mottling and blotch symptoms in N. tabacum leaves (Rodriguez-Cerezo et al. 1991). However, according to many studies, it was not known whether or not mutations in the viral proteins or NTRs affected symptom expression independent of their effects on virus accumulation, movement, or both.

Potato virus A (PVA) is a typical Potyvirus species. It contains a single-stranded positive-sense RNA genome $(9,565$ to 9,567 nucleotides) that encodes a single polyprotein of 3,059 amino acids (aa) (Kekarainen et al. 1999). PVA has a narrow host range limited to species in the family Solanaceae and can be experimentally propagated, e.g., in N. tabacum and N. benthamiana (Bartels 1971). However, isolates or strains of PVA differ in their ability to systemically infect certain hosts (Rajamäki et al. 1998). PVA isolate M (Valkonen et al. 1995) is virulent on potato (Solanum tuberosum) but does not infect Nicandra physaloides var. Black Pod systemically, except at very young growth stages (Rajamäki and Valkonen 1999). In contrast, PVA isolate B11 (Puurand et al. 1996) is virulent on seedlings of Nicandra physaloides regardless of the growth stage (Rajamäki and Valkonen 1999) but does not infect potato cultivars systemically (Valkonen et al. 1995). Comparison of the genomic sequences of these PVA isolates and mutational studies on chimeric viruses indicate that the N-proximal Met5 of $6 \mathrm{~K} 2$ protein (as compared with Val5 at this position in PVAM) enhances virulence in Nicandra physaloides (Rajamäki and Valkonen 1999). Our unpublished data on infectious chimeric PVA constructs suggest that Met5 of $6 \mathrm{~K} 2$ is associated with internal net necrosis symptoms induced in PVA-infected tubers of $S$. commersonii during cold storage $\left(4^{\circ} \mathrm{C}\right)$ (M. L. Rajamäki and J. Valkonen, unpublished data). These observations provided some preliminary indications that $6 \mathrm{~K} 2$ could be a determinant of symptom induction in PVA.

The $6 \mathrm{~K} 2$ protein in TEV and PVA (53 aas in both viruses) is membrane-bound (Merits et al. 2002; Restrepo-Hartwig and Carrington 1994) and is believed to anchor the viral replication complex to the site of replication on the endoplasmic reticulum (ER) (Li et al. 1997; Schaad et al. 1997). The TEV 6K2 protein 
amino acids 22 through 44 form a hydrophobic domain and may span the lipid bilayer, exposing the $\mathrm{N}$ - and $\mathrm{C}$ - terminus of the protein to the cytoplasmic side of the membrane (Shaad et al. 1997). The NIa proteinase (NIa-Pro) cleavage sites (CI/6K2 and $6 \mathrm{~K} 2 / \mathrm{VPg}$ junctions) flanking the $6 \mathrm{~K} 2$ are required for replication of TEV (Restrepo-Hartwig and Carrington 1994) and PVA (Merits et al. 2002), implying that both $6 \mathrm{~K} 2$ termini are accessible to NIa-Pro in the cytoplasmatic side of the membrane.

The aim of this study was to carry out a more detailed analysis on the functions of $6 \mathrm{~K} 2$ in movement and symptom induction by PVA. To this end, $6 \mathrm{~K} 2$ was modified by insertion of $6 \times \mathrm{His}$ or by deleting different proportions of the $6 \mathrm{~K} 2$-encoding region. Our data show that the $6 \mathrm{~K} 2$ is a determinant for systemic infection and symptom induction in $N$. benthamiana and a determinant of systemic infection in N. tabacum plants. Furthermore, the data indicate that these functions are determined by $6 \mathrm{~K} 2$ in a host-specific manner and that viral longdistance movement and symptom-induction functions of $6 \mathrm{~K} 2$ are independent.

\section{RESULTS}

Deletions and insertions

in the $6 \mathrm{~K} 2$ protein inhibit infection in $N$. tabacum plants.

Different proportions of the $\mathrm{N}$-proximal part were deleted from the $6 \mathrm{~K} 2$ protein $(53 \mathrm{aa})$ (constructs p6K $2 \Delta 1-\mathrm{p} 6 \mathrm{~K} 2 \Delta 4$ )

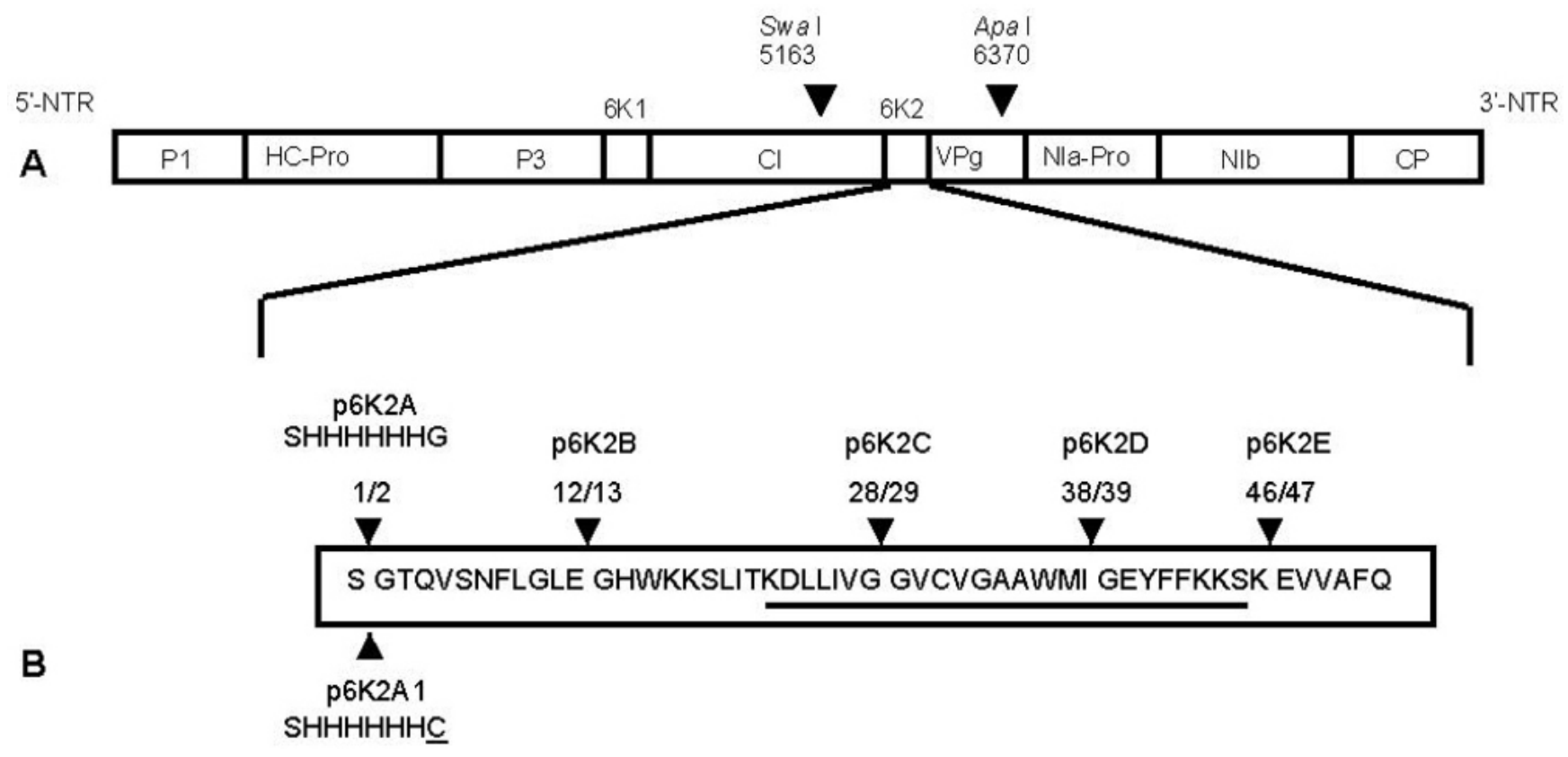

Fig. 1. Schematic map of the viral constructs based on the infectious cDNA of Potato virus A isolate B11 (PVA-B11). A, The genome of PVA contains a $5^{\prime}$ nontranslated region (5'-NTR) and a $3^{\prime}$-NTR, which are not shown. Positions of the unique SwaI and ApaI restriction sites in the viral cDNA are indicated. The virus genome encodes a polyprotein that is autoproteolytically processed to mature proteins, of which the positions are shown. P1= proteinase, HC$\mathrm{Pro}=$ helper component proteinase, $\mathrm{P} 3=$ third protein, $6 \mathrm{~K} 1=6 \mathrm{kDa}$ protein, $\mathrm{CI}=$ cylindrical inclusion protein, $6 \mathrm{~K} 2=6 \mathrm{kDa}$ protein, $\mathrm{VPg}=\mathrm{viral}$ genomelinked protein, NIa-Pro = proteinase, $\mathrm{NIb}=$ replicase, and $\mathrm{CP}=$ coat protein. $\mathbf{B}$, The amino acid (aa) sequence of the $6 \mathrm{~K} 2$ protein (53 aa residues), in which the hydrophobic domain is underlined. Positions of the $6 \times$ His inserts in the insertion mutants are indicated by the positions of the flanking aa residues in $6 \mathrm{~K} 2$ and an arrowhead (above the sequence). In the insertion mutant p6K2A1, Gly2 is substituted for cysteine (underlined). C, Substitution Gly2Cys was introduced also to the wild-type PVA-B11 cDNA to create mutant $\mathrm{p} 6 \mathrm{~K} 2 \mathrm{G} \rightarrow \mathrm{C}$. D, In deletion mutants, various proportions of the $6 \mathrm{~K} 2$-encoding region were deleted (dotted line). Positions of the N-terminal amino acid of the deletion mutants are indicated (numbered according to wild-type 6K2). 

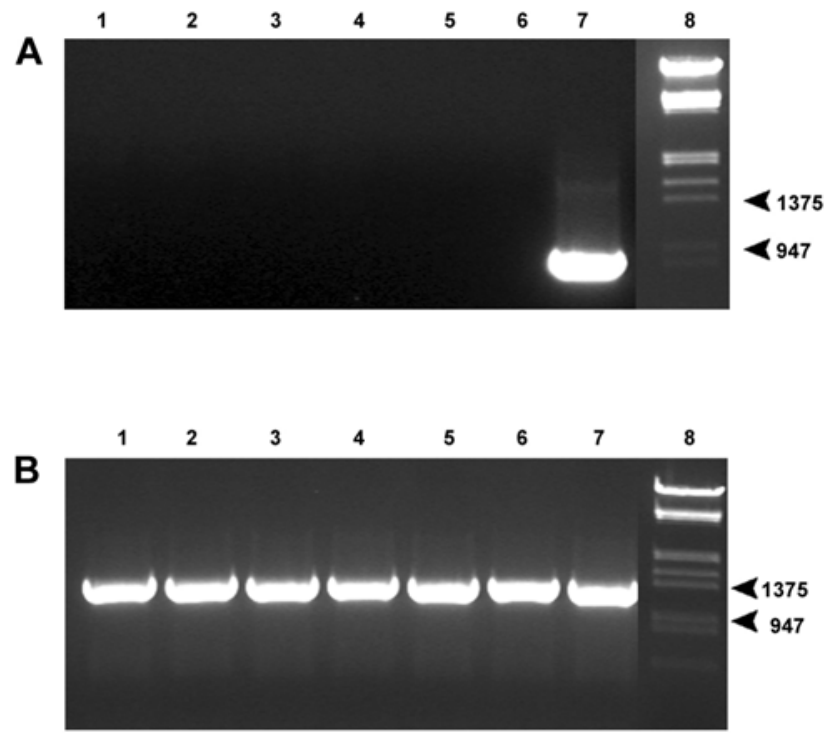

Fig. 2. Reverse transcription-polymerase chain reaction-based detection of Potato virus A (PVA) in the upper noninoculated leaves of Nicotiana tabacum plants that were coinoculated with the wild-type PVA-B11 and the insertion mutants (p6K2A through p6K2E). A, Amplification with the primers $6 \times$ His-F and Apa-R, which detects the viruses containing the $6 \times$ His insert. B, Amplification with primers Swa-F and Apa-R, which detects wild-type PVA-B11 and any of the insertion mutants. Lane 1, PVA-B11 + p6K2A; lane 2, PVA-B11 + p6K2B; lane 3, PVA-B11 + p6K2C; lane 4, PVA-B11 + p6K2D; lane 5, PVA-B11 + p6K2E; lane 6, PVA-B11; lane 7, $10 \mathrm{ng}$ of control plasmid (p6K2A); and lane 8, lambda EcoRI/HindIII DNA marker. Position of the markers of 1,375 and $947 \mathrm{bp}$ are indicated with arrowheads. The same cDNA preparation (sample) was used in both amplifications. In A, amplification was only obtained using the control plasmid as a template (lane 7), indicating no detectable amounts of any insertion mutant. In B, amplification products of a similar size were obtained in all samples, indicating that all plants were systemically infected only with wild-type PVA-B11.
(Fig. 1D) of PVA-B11 in a plasmid containing the full-length infectious cDNA of PVA-B11 (Puurand et al. 1996). N. tabacum seedlings were mechanically inoculated with the capped in vitro transcripts of the mutant viruses in two experiments (a total of six plants per mutant). Inoculated leaves and upper noninoculated leaves were tested for PVA 14 and 21 days postinoculation (dpi) by double-antibody sandwichenzyme-linked immunosorbent assay (DAS-ELISA). Results were negative, whereas plants inoculated with the wild-type (wt) PVA-B11 were systemically infected and contained high titers of PVA antigen (data not shown). Subsequently, another set of PVA mutants was made by inserting six His residues $(6 \times$ His) to five different positions in $6 \mathrm{~K} 2$ (mutants p6K2A through p6K2E) (Fig. 1B), and N. tabacum seedlings were inoculated with in vitro transcripts of these insertion mutants, as before. Inoculated and upper uninoculated leaves were tested for PVA by DAS-ELISA (Table 1), as before, and also by reverse transcription-polymerase chain reaction (RT-PCR) (data not shown), with negative results in both assays. Therefore, all of the deleted regions of the PVA $6 \mathrm{~K} 2$ protein were essential for infection, and all of the $6 \times \mathrm{His}$ insertions disturbed critical viral functions needed for infection in $N$. $t a-$ bacum plants. Mechanical coinoculation of the in vitro transcripts derived from the insertion constructs (p6K2A through p6K2E) with wt PVA-B11 did not result in systemic infection with the insertion mutants but only with wt PVA-B11, as detected by RT-PCR using the primer pairs Swa-F/Apa-R (amplifies the wt PVA-B11 and the insertion constructs) and $6 \times$ HisF/Apa-R (amplifies only the insertion constructs) (Fig. 2).

\section{A point mutation in $6 \mathrm{~K} 2 \mathrm{~N}$-terminus restores long-distance movement functions of an insertion mutant in $N$. benthamiana.}

A total of eight $N$. benthamiana plants were inoculated with the five insertion mutants or wt PVA-B11 in two independent experiments. Vein chlorosis and mild yellowing symptoms were observed in the plants inoculated with wt PVA-B11, and they tested virus-positive in DAS-ELISA. In contrast, the inoculated and upper noninoculated leaves of plants inoculated

Table 1. Accumulation of Potato virus A (PVA) coat protein antigen in the leaves of Nicotiana tabacum and N. benthamiana

\begin{tabular}{|c|c|c|c|c|c|}
\hline \multirow[b]{3}{*}{ Viral construct $^{\mathrm{a}}$} & \multicolumn{2}{|c|}{ N. tabacum } & \multicolumn{3}{|c|}{ N. benthamiana } \\
\hline & \multicolumn{4}{|c|}{ ELISA } & \multirow[b]{2}{*}{ Symptoms $^{\mathrm{d}}$} \\
\hline & $\mathbf{n}^{\mathbf{b}}$ & $n g(S E)^{c}$ & $\mathbf{n}^{\mathbf{b}}$ & $n g(S E)^{c}$ & \\
\hline Wt PVA-B11 & $10 / 10$ & $3,398(469)$ & $8 / 8$ & $4,076(317)$ & + \\
\hline \multicolumn{6}{|l|}{ Point mutation } \\
\hline $\mathrm{p} 6 \mathrm{~K} 2 \mathrm{G} \rightarrow \mathrm{C}$ & $3 / 3$ & $2,878(449)$ & $3 / 3$ & $4,484(502)$ & + \\
\hline \multicolumn{6}{|l|}{$6 \times$ His insertion mutants } \\
\hline p6K2A & $0 / 10$ & 0 & $1 / 8^{\mathrm{e}}$ & $3903^{\mathrm{e}}$ & - \\
\hline p6K2B & $0 / 10$ & 0 & $0 / 8$ & 0 & - \\
\hline p6K2D & $0 / 10$ & 0 & $0 / 8$ & 0 & - \\
\hline p6K2E & $0 / 10$ & 0 & $0 / 8$ & 0 & - \\
\hline \multicolumn{6}{|l|}{ Serial propagation } \\
\hline $\mathrm{p} 6 \mathrm{~K} 2 \mathrm{~A} 1$ & $0 / 6^{\mathrm{f}}$ & $0^{\mathrm{f}}$ & $6 / 6$ & $4,750(167)$ & - \\
\hline p6K2A1 2nd passage & $0 / 3$ & 0 & $3 / 3$ & $4,253(517)$ & - \\
\hline p6K2A1 3rd passage & $6 / 6$ & $3,970^{\mathrm{g}}(936)$ & $6 / 6$ & $4,331^{\mathrm{h}}(276)$ & + \\
\hline
\end{tabular}

a "Passage" indicates that p6K2A1 was serially propagated by mechanical inoculation.

${ }^{\mathrm{b}}$ The number of plants that tested positive to the total number of plants tested in two experiments.

${ }^{c}$ Amounts of PVA antigen (ng per g of leaf), as determined by double antibody sandwich-enzyme-linked immunosorbent assay using known amounts of PVA virions for comparison. S.E. = standard error. Results on virus accumulation in the upper noninoculated leaves are shown, unless stated otherwise.

${ }^{\mathrm{d}}$ Symptoms were observed 14 and 21 days postinoculation. The presence $(+)$ or absence $(-)$ of typical PVA symptoms (vein chlorosis and mosaic) in the upper noninoculated leaves of $N$. benthamiana are indicated. $N$. tabacum plants did not develop symptoms following inoculation with any virus tested.

${ }^{\mathrm{e}}$ Viral amounts correspond to a single plant that was found to be infected with a spontaneously born mutant (p6K2A1).

${ }^{\mathrm{f}}$ Low but readily detectable amounts of PVA ( $312 \mathrm{ng} / \mathrm{g}$ of leaf) were detected in two inoculated leaves in two plants, but no virus was detected in the upper noninoculated leaves.

$\mathrm{g}$ Viral amounts correspond to the deletion mutant $6 \mathrm{~K} 2 \Delta 4 \mathrm{HCT}$.

${ }^{\mathrm{h}}$ Viral amounts correspond to mixed infection of p6K2A1 and the deletion mutant $6 \mathrm{~K} 2 \Delta 4 \mathrm{HCT}$. 
with the insertion mutants were symptomless and virus-negative, except one plant inoculated with one of the insertion mutants (p6K2A, Fig. 1B) in the second experiment. Virus titers in the systemically infected leaves of this plant were no lower than those in the plants inoculated with wt PVA-B11, but no symptoms were observed (Table 1 ). RT-PCR using the $6 \times \mathrm{His}-$ F/Apa-R primer combination indicated that the $6 \times$ His insertion was present in the virus progeny of the symptomless plant (data not shown). Subsequently, a 1,208-bp fragment encompassing the region encoding the $\mathrm{C}$-proximal part of the cylindrical inclusion protein $(\mathrm{CI}), 6 \mathrm{~K} 2$, and $\mathrm{VPg}$, which included the unique $S w a \mathrm{I}$ and $A p a \mathrm{I}$ restriction sites (Fig. 1A), was RTPCR-amplified from the virus progeny of the symptomless systemically infected plant, and was cloned and sequenced. Analysis on four independently amplified clones revealed a single point mutation in codon 2 of $6 \mathrm{~K} 2$, just downstream from the $6 \times$ His insert. The point mutation resulted in the substitution Gly2Cys (aa residue 8 in the $6 \times$ His-containing $6 \mathrm{~K} 2$ protein, Fig. 1B). No other mutations were detected in the analyzed clones.

To exclude any mutations that might have occurred in other parts of the viral genome and which might have facilitated systemic infection of p6K2A, the SwaI-ApaI fragment of the wt PVA-B11 cDNA was replaced with the corresponding, aforementioned, cloned and sequenced fragment containing the Gly2Cys substitution. The new virus construct was designated p6K2A1 (Fig. 1B). Transcripts from p6K2A1 were inoculated to $N$. benthamiana and $N$. tabacum seedlings in two experi- ments, as before. No symptoms were observed in the inoculated plants. However, DAS-ELISA indicated that all N. benthamiana plants were systemically infected (Table 1), which was also confirmed by RT-PCR (Fig. 3A', lane 3). RT-PCR using the primer pair $6 \times$ His-F/Apa-R indicated that the $6 \times$ His insertion was present in the virus progeny (Fig. 3B', lane 3). In contrast to $N$. benthamiana, no PVA was detected in the upper noninoculated leaves of $N$. tabacum plants by DAS-ELISA and RT-PCR. In two N. tabacum plants of the six plants inoculated, however, low but readily detectable amounts of PVA antigen were found in the inoculated leaves by DAS-ELISA (Table 1).

Protoplasts of $N$. benthamiana and N. tabacum were inoculated with in vitro transcripts of p6K2A and p6K2A1. Detectable amounts of negative-strand viral genomic RNA (the replicative form) were observed with both constructs in the protoplasts of both hosts (Fig. 4). However, the amounts of p6K2A were lower than those with p6K2A1 (Fig. 4, A4-NS as compared with A5-NS and B4-NS with B5-NS). These results were consistent with the results from $\mathrm{p} 6 \mathrm{~K} 2 \mathrm{~A}$ - and p6K2A1-detection in leaves by ELISA (discussed above).

The Gly2Cys substitution (including a unique Bsp1407I restriction site discussed below) was introduced to $6 \mathrm{~K} 2$ in $\mathrm{wt}$ PVA-B11 cDNA by site-directed mutagenesis. The construct was designated as $\mathrm{p} 6 \mathrm{~K} 2 \mathrm{G} \rightarrow \mathrm{C}$ (Fig. 1C). This PVA mutant infected $N$. benthamiana systemically, causing symptoms (Fig. 5B) similar to wt PVA-B11 (Fig. 5A), and accumulated to titers no less than those of wt PVA-B11 (Table 1). Also,

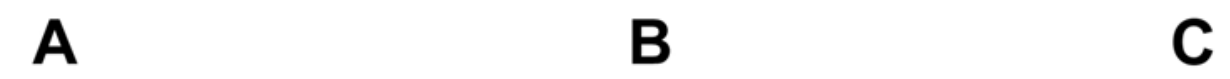

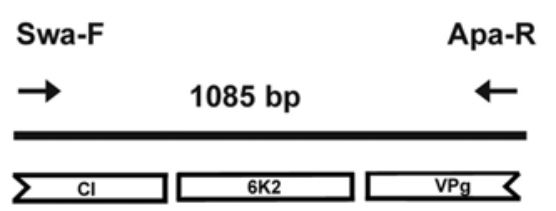

LQFSGTQVLN
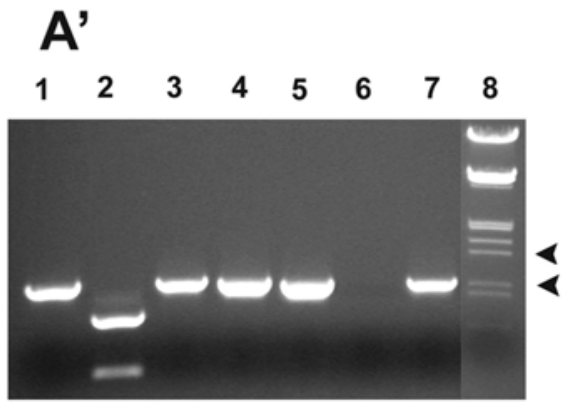

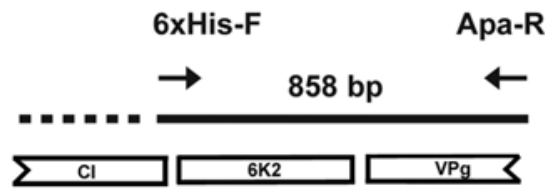

LQFSHHHHHHCTQVLN
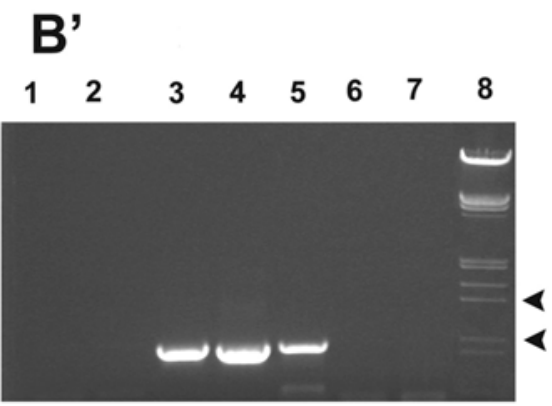

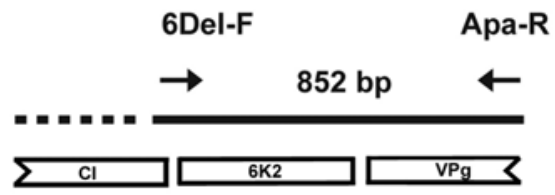

LQFSHHQVLN

Fig. 3. The strategy of reverse transcription-polymerase chain reaction (RT-PCR)-based detection of A, wild-type PVA-B11 B, insertion mutant p6K2A1 and $\mathbf{C}$, the deletion mutant $(6 \mathrm{~K} 2 \Delta 4 \mathrm{HCT})$ in the upper noninoculated leaves of Nicotiana benthamiana and N. tabacum plants. The results (ethidium bromide-stained agarose gels) of RT-PCR amplification using A', primer pair Swa-F and Apa-R, B', the 6×His insert-specific primer 6×His-F and Apa-R, and C', the deletion mutant specific primer 6Del-F and the Apa-R are shown below the schematic presentation of primers and their orientation. Bold lines in A to $\mathrm{C}$ indicate the amplified region, above which the expected size of the amplification product is shown (bp). Below the bold line, the three last amino acid (aa) residues of CI and the first seven aa residues of $6 \mathrm{~K} 2$ are presented. The first aa of $6 \mathrm{~K} 2$ is depicted with an asterisk $(*)$. Underlined aa sequences identify the regions to which pr imers $6 \times \mathrm{His}-\mathrm{F}(\mathrm{B})$ and $6 \mathrm{Del}-\mathrm{F}(\mathrm{C})$ hybridize. Samples from the left: $N$. benthamiana inoculated with wild-type PVA-B11 (lane 1), p6K2G $\rightarrow \mathrm{C}$ (lane 2), and with p6K2A1, first (lane 3), second (lane 4), and third (lane 5) passages. The last two samples are from N. tabacum plants inoculated with virus from $N$. benthamiana following the second (lane 6) and third (lane 7) passages of p6K2A1. The lambda EcoRI/HindIII DNA marker is in lane 8 (positions of the markers of $1,375 \mathrm{bp}$ and $947 \mathrm{bp}$ are indicated with arrowheads). PCR products amplified with the Swa-F + Apa-R primers (A') were subjected to restriction analysis using Bsp 1407I, which only cleaves the restriction site present in construct p6K2G $\rightarrow \mathrm{C}$ (lane 2 ). Using primers $6 \times \mathrm{His}$ F (B'), amplification products were obtained only from the $N$. benthamiana plants inoculated with construct p6K2A1 (lanes 3 to 5), whereas amplification using the primer 6Del-F (C') detected the spontaneously born deletion mutant $(6 \mathrm{~K} 2 \Delta 4 \mathrm{HCT})$ following the third passage both in $N$. benthamiana (lane 5) and $N$. tabacum (lane 7). Note that $N$. benthamiana was infected both with p6K2A1 and the deletion mutant $6 \mathrm{~K} 2 \Delta 4 \mathrm{HCT}$ following the third passage (B', lane 5 as compared with C', lane 5) in contrast to $N$. tabacum, which was infected with the deletion mutant only (B', lane 7 as compared with C', lane 7). 
p6K2G $\rightarrow$ C infected $N$. tabacum plants systemically and accumulated to high titers (Table 1 ). The $6 \mathrm{~K} 2$ region was RT-PCRamplified from the progeny viruses of the systemically infected leaves and was analyzed by restriction with Bsp1407I. The amplification products were completely digested (Fig. $3 \mathrm{~A}^{\prime}$, lane 2), indicating no reversion of the mutated sequence. These results showed that Cys 2 in the $6 \mathrm{~K} 2$ protein causes no attenuation of symptoms in $N$. benthamiana and that both Gly2 (wt PVA-B11) and Cys2 (p6K2G $\rightarrow$ C) are compatible for systemic infection of $N$. tabacum plants.

\section{Symptom induction and systemic infection are restored by a spontaneous deletion within the $6 \times$ His-tagged $6 \mathrm{~K} 2$.}

The mutant p6K2A1 was serially propagated by mechanical inoculation in $N$. benthamiana plants. In the first infection cycle (or passage) in vitro transcripts were used as the inoculum. Symptomless systemic infection was detected in $N$. benthamiana (Fig. 5C1), as before. In the second passage, sap extracted from the systemically infected leaves was used for inoculum. Again, symptomless systemic infection (Fig. $5 \mathrm{C} 2$ ) was detected by DAS-ELISA, and virus titers were comparable to those of wt PVA-B11 (Table 1). RT-PCR using the primer pair $6 \times$ His-F/Apa-R indicated that the $6 \times \mathrm{His}$ insert was present in progeny viruses (Fig. 3B', lane 4). Inoculation of $N$. tabacum plants with the same inoculum as used for $N$. benthamiana resulted in no systemic infection, as de-

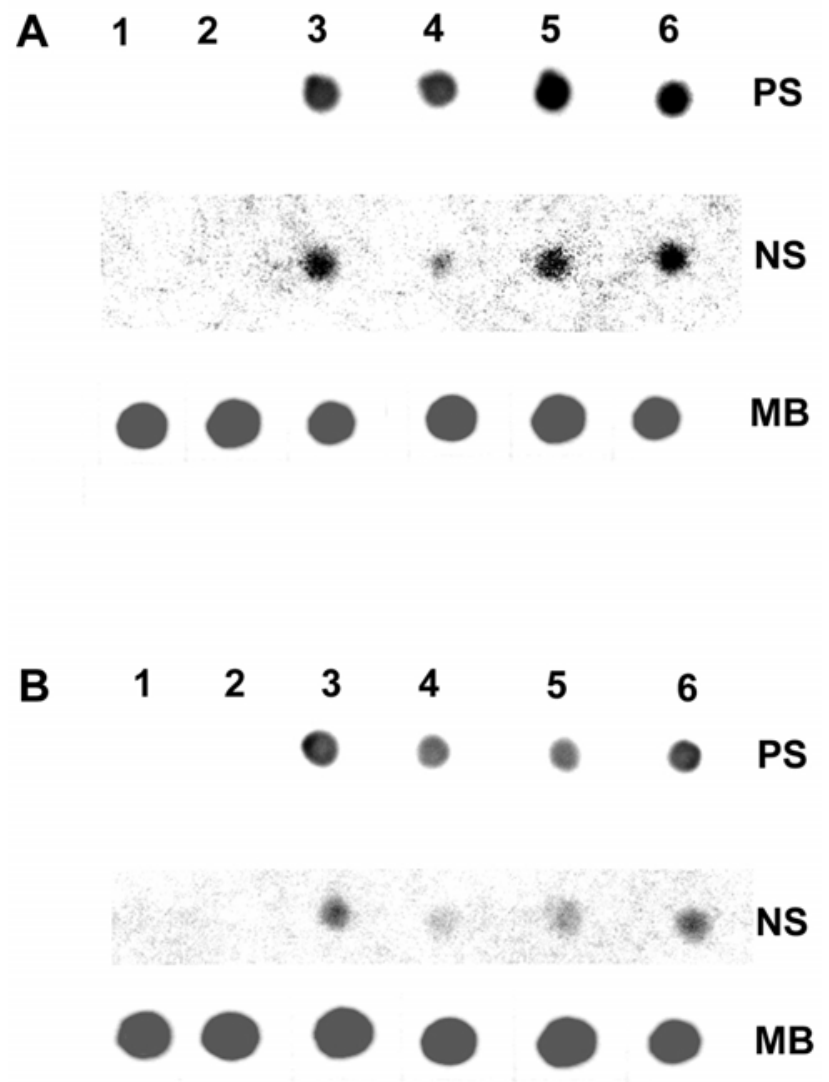

Fig. 4. Detection of viral positive strand (PS) RNA and negative strand (NS) RNA in A, Nicotiana benthamiana and B, N. tabacum protoplasts 24 $\mathrm{h}$ postelectroporation with viral in vitro transcripts. Equal amounts of RNA were dotted on the membrane, as determined by methylene blue (MB) straining of the membranes. The membrane was first hybridized with a probe for NS and the results were obtained, after which the probe was stripped off and the membrane was subsequently hybridized with a probe for detection of PS. $1=$ mock-inoculated protoplasts, $2=$ noninfectious construct p6K2 $24 ; 3$ = wild-type PVA-B11; 4 = p6K2A; 5 $=\mathrm{p} 6 \mathrm{~K} 2 \mathrm{~A} 1 ;$ and $6=\mathrm{p} 6 \mathrm{~K} 2 \Delta 4 \mathrm{HCT}-1$. termined by DAS-ELISA and RT-PCR (Table 1; Fig. 3A', lane 6).

Following the third passage however, all inoculated $N$. benthamiana plants showed vein chlorosis and mild yellowing symptoms in systemically infected leaves (Fig. 5C3), which is characteristic of infection with wt PVA-B11 (Fig. 5A). Also, N. tabacum plants were systemically infected (Table 1; Fig. $3 A^{\prime}$, lane 7). Virus titers were similar to those of wt PVA-B11 (Table 1). Sequence analyses on the progeny viruses in two plants of $N$. benthamiana and $N$. tabacum revealed an identical deletion in $6 \mathrm{~K} 2$. The deletion had resulted in a loss of the codons for the last four histidine residues of the $6 \times$ His insert as well as the codons for Cys 2 and Thr3 of $6 \mathrm{~K} 2$. Due to the deletion of the 6 aa residues, the $6 \mathrm{~K} 2$ protein of the spontaneously mutated virus (designated as $6 \mathrm{~K} 2 \Delta 4 \mathrm{HCT}$ ) was reduced to the original (wild-type) size (53 aa). However, as compared with wt PVA-B11, the positions of the second (Gly) and the third (Thr) aa residue of wt PVA-B11 were occupied each with a His residue in $6 \mathrm{~K} 2 \Delta 4 \mathrm{HCT}$ (Fig. 5C). The deletion mutant $6 \mathrm{~K} 2 \Delta 4 \mathrm{HCT}$ was reconstituted in the infectious PVA cDNA in the same manner as described for p6K2A1 above and designated as $6 \mathrm{~K} 2 \Delta 4 \mathrm{HCT}-1$. It replicated in inoculated $N$. tabacum protoplasts to higher amounts than did p6K2A1 (Fig. 4, B6NS as compared with B5-NS) and also to high titers in N. benthamiana protoplasts (Fig. 4A).

Analysis of the plants infected following the third virus passage was continued by RT-PCR, using a new primer pair (6Del-F/Apa-R) specifically detecting the spontaneous deletion mutant $6 \mathrm{~K} 2 \Delta 4 \mathrm{HCT}$ and the primer pair $6 \times \mathrm{His}-\mathrm{F} / \mathrm{Apa}-\mathrm{R}$ specific to the $6 \times$ His insert. Only the deletion mutant $6 \mathrm{~K} 2 \Delta 4 \mathrm{HCT}$ was detected in the systemically infected $N$. $t a-$ bacum leaves (Fig. 3B' and C', lane 7). These data showed that partial deletion of $6 \times \mathrm{His}$ insert from $6 \mathrm{~K} 2$ was required for systemic infection of $N$. tabacum plants. In contrast, all $N$. benthamiana plants were systemically infected with a mixture of $6 \mathrm{~K} 2 \Delta 4 \mathrm{HCT}$ and p6K2A1 (Fig. 3B' and C', lane 5), suggesting that low, undetectable amounts of $6 \mathrm{~K} 2 \Delta 4 \mathrm{HCT}$ may have existed in the leaves of $N$. benthamiana (systemically infected following the second passage) that were used as inoculum for the third virus passage.

\section{DISCUSSION}

The results of this study indicate that the $6 \times \mathrm{His}$ inserts in the $6 \mathrm{~K} 2$ protein interfered with important viral functions required for successful infection of the Nicotiana hosts. However, a single aa substitution Gly2Cys adjacent to the most $\mathrm{N}$ terminal $6 \times$ His insertion was sufficient to alleviate the restriction of viral long-distance movement and allowed virus accumulation to normal, high levels in the systemically infected leaves of $N$. benthamiana, but it was insufficient for restoring symptom induction by PVA. Thus, differences in symptom expression were not associated with differences in virus accumulation. Indeed, the further spontaneous deletion of four His residues, Gly2, and Thr3 (mutant $6 \mathrm{~K} 2 \Delta 4 \mathrm{HCT}$ ) was needed for typical wt PVA-B11-type symptom expression in the systemically infected leaves of $N$. benthamiana. Taken together, the data indicated that a $6 \times \mathrm{His}$ insert in the N-terminus of $6 \mathrm{~K} 2$ played a major role in attenuation of symptoms in $N$. benthamiana and that Gly 2 and Thr3 of $6 \mathrm{~K} 2$ per se were not significant for symptom induction.

In previous studies, a $\mathrm{P} 3+6 \mathrm{~K} 1$ polyprotein of PPV (Sáenz et al. 2000) and a TEV polyprotein containing 6K2 (Chu et al. 1997) affected symptom expression, which supports the possibility that the membrane-binding $6 \mathrm{~K}$ proteins are important for symptom induction. (The $6 \mathrm{~K} 1$ protein contains hydrophobic stretches predicted to mediate membrane-bind- 

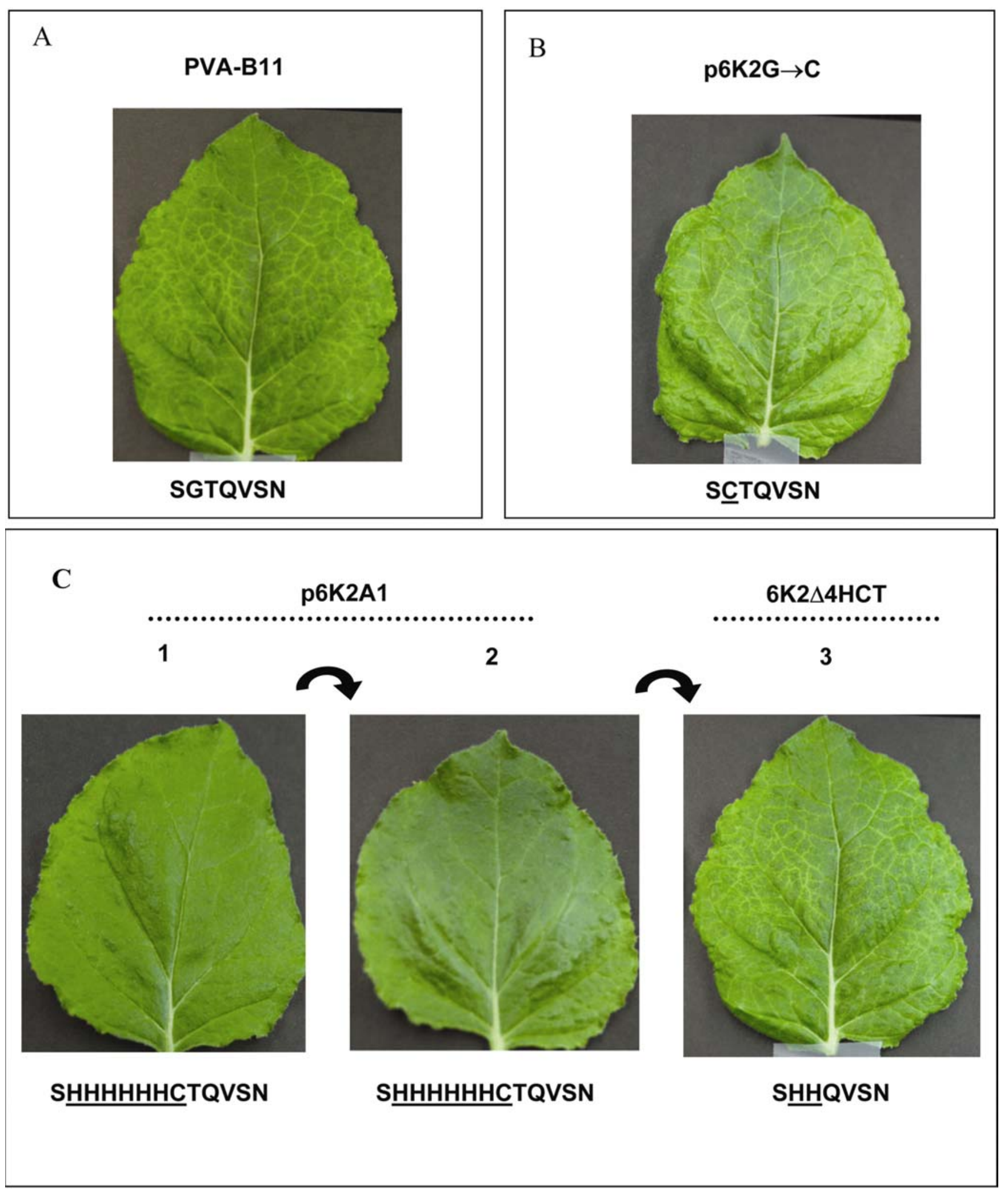

Fig. 5. Different symptom phenotypes in Nicotiana benthamiana plants inoculated with A, wild-type PVA-B11 and B, the 6K2 Gly2Cys substitution mutant p6K2G $\rightarrow$ C, as compared with the symptoms observed in plants inoculated with the $6 \times$ His insertion mutant p6K2A1 following the $\mathbf{C 1}$, first, $\mathbf{C 2}$, second, and C3, third passages. The seven most N-terminal amino acid (aa) residues of $6 \mathrm{~K} 2$ in the respective virus are shown below photographs. The underlined aa residues differ from the wild-type sequence. Note that p6K2A1 causes no symptoms (C1 and C2) until after the third passage (C3), when symptoms similar to wild-type PVA-B11 are observed. This is due to a spontaneously born deletion mutant $(6 \mathrm{~K} 2 \Delta 4 \mathrm{HCT})$ that also caused the symptoms shown in C3 when inoculated to healthy plants in additional experiments. 
ing similar to those in 6K2 [Riechmann et al. 1992]). Consequently, alleviation of symptoms observed in the current study might be associated with altered $6 \mathrm{~K} 2$-mediated membrane interactions due to the $6 \times \mathrm{His}$ insert. Other proteinmembrane interactions, notably those between the viral $\mathrm{CP}$ and chloroplast membranes, have been proposed to cause chlorosis symptoms by Potato virus $Y$ (genus Potyvirus) (Naderi and Berger 1997) and Tobacco mosaic virus (TMV, genus Tobamovirus) (Culver 2002) in N. tabacum leaves. Binding of $6 \mathrm{~K} 2$ to ER (Restrepo-Hartwig and Carrington 1994) is hypothesized to anchor the replication complex putatively composed of several viral and host proteins to the site of replication (Li et al. 1997; Schaad et al. 1997). Transgenic $N$. tabacum cells expressing TEV 6K2 (Restrepo-Hartwig and Carrington 1994) and nontransgenic N. tabacum cells infected with TEV (Schaad et al. 1997) show many novel membraneous structures, consistent with important 6K2-membrane interactions. However, the two $6 \times \mathrm{His}$ inserts and other mutations at the N-proximal part of $6 \mathrm{~K} 2$ characterized for their phenotypes in this study are not located within the central hydrophobic domain of the protein (Fig. 1B). Therefore, they probably did not prevent membrane binding of $6 \mathrm{~K} 2$. Nevertheless, owing to the multiple functions of ER (Staehelin 1997), it is hypothesized that even more subtle changes in the conformation and membrane-binding abilities of $6 \mathrm{~K} 2$, such as those possibly specific to $\mathrm{p} 6 \mathrm{~K} 2 \mathrm{~A}$ and $\mathrm{p} 6 \mathrm{~K} 2 \mathrm{~A} 1$, might alleviate the deleterious virus-host interactions that normally result in mosaic and vein chlorosis symptoms typical of PVA-B11 infections in N. benthamiana.

The mutant p6K2A replicated in $N$. benthamiana and $N$. tabacum protoplasts to low levels and the Gly2Cys substitution (mutant p6K2A1) increased viral RNA accumulation in the protoplasts of both hosts, which was consistent with the accumulated levels of viral $\mathrm{CP}$ in the leaves of inoculated plants. However, effects of $6 \mathrm{~K} 2$ were host-specific, since the substitution Gly2Cys alleviated restricted long-distance movement in $N$. benthamiana but not in N. tabacum plants. In N. tabacum, a further mutation by spontaneous deletion of four His residues and Gly2 and Thr3 from the $6 \mathrm{~K} 2$ of p6K2A1 (mutant $6 \mathrm{~K} 2 \Delta 4 \mathrm{HCT}$ ) was required to restore systemic infection. Differences in how N. tabacum and N. benthamiana support viral movement functions are evident also from a previous study in which substitution of Ser258, Thr261, and Ser265 with negatively charged aspartate residues in the $30 \mathrm{~K}$ movement protein of TMV inhibited cell-tocell movement of TMV in $N$. tabacum but did not restrain cell-to-cell and long-distance movement in $N$. benthamiana (Waigmann et al. 2000). Taken together, these data indicated that $N$. tabacum is more restrictive to systemic virus infection than $N$. benthamiana and that Gly 2 and Thr3 of $6 \mathrm{~K} 2$ per se were not crucial for long-distance movement of PVA. The mechanism by which the 6K2-mediated accumulation and systemic infection functions of PVA differ in $N$. benthamiana and $N$. tabacum remains to be determined in future studies.

Significant reduction of PVA-B11 accumulation in $N$. tabacum protoplasts and leaves due to $6 \times$ His insertions in $6 \mathrm{~K} 2$ is consistent with a previous study in which 5-aa inserts between aa positions 1 and 2 and 6 and 7 at the $6 \mathrm{~K} 2 \mathrm{~N}$-terminus prevented detectable propagation of PVA-B11 in $N$. $t a-$ bacum protoplasts (Kekarainen et al. 2002). Also, wt PVAB11 failed to complement the infectivity of the $6 \mathrm{~K} 2$ mutants in N. tabacum in this study, which is consistent with previous studies indicating that the $6 \mathrm{~K} 2$ of TEV mediates its functions in cis (Schaad et al. 1996). On the other hand, the data of this study are different from those obtained with TEV, because a $7 \mathrm{xHis}$ insert between aa positions 1 and 2 of $6 \mathrm{~K} 2$ in TEV did not detectably interfere with the systemic infection of TEV in
N. tabacum plants (Schaad et al. 1996). The different results may be due to the different $N$. tabacum cultivars used in our study (Samsun nn) and the previous study on TEV (Xanthi nc), since our data indicated a host-specific mode of action for $6 \mathrm{~K} 2$. Alternatively, there could be some as-yet-unknown differences in how $6 \mathrm{~K} 2$ mediates the replicative functions in PVA and TEV. Such differences are suggested by detection of a 6K2-NIa polyprotein in cells infected with TEV (Schaad et al. 1996), in contrast to those infected with PVA that contain a CI-6K2 polyprotein (Merits et al. 2002). However, the replication complexes of these viruses are not yet characterized, and more detailed knowledge on participation of $6 \mathrm{~K} 2$ in the putative replication complex is lacking. Furthermore, while putative conformational changes due to the $6 \times \mathrm{His}$ insert at the $6 \mathrm{~K} 2 \mathrm{~N}$-terminus might affect the formation of a replication complex, they may also interfere with polyprotein processing, making the cleavage site less accessible to NIa-Pro and thereby may debilitate infectivity of PVA. The latter mentioned possibility is supported by previous studies showing that proteolytic cleavages at the $\mathrm{CI} / 6 \mathrm{~K} 2$ and $6 \mathrm{~K} 2 / \mathrm{VPg}$ junctions are required for viral replication (Merits et al. 2002; Restrepo-Hartwig and Carrington 1994).

The mutations in $6 \mathrm{~K} 2$ that restored systemic infection in plants also increased virus accumulation in protoplasts. These findings raise a question as to how virus propagation and movement functions may be mediated by $6 \mathrm{~K} 2$. While not yet known, it may be hypothesized that $6 \mathrm{~K} 2$ could regulate spatial and temporal binding of the putative viral replication and movement complexes to membranes (discussed above). A CI-6K2 polyprotein is still abundantly found in cells upon completion of PVA polyprotein processing (Merits et al. 2002). CI is a potyviral RNA helicase (Laín et al. 1990) important to virus propagation (Kekarainen et al. 2002) and also functions as a viral movement protein (Carrington et al. 1998). The CI-6K2 polyprotein is predicted to possess membrane-binding activities owing to $6 \mathrm{~K} 2$ and to have viral movement, RNA-binding, and helicase activities conferred by CI. In Carnation mottle virus (genus Carmovirus), the p7 protein binds RNA, whereas the p9 protein is an integral membrane protein. These two proteins are believed to interact via their $\beta$-sheet domains and thereby mediate the intracellular and cell-to-cell movement of viral RNA along ER and the membranes of plasmodesmata (Vilar et al. 2002). Therefore, our data propose that the CI-6K2 polyprotein may be the key for viral propagation and movement functions mediated by $6 \mathrm{~K} 2$.

\section{MATERIALS AND METHODS}

\section{Total RNA extraction, oligonucleotides, RT-PCR, and DNA sequencing.}

Total RNA extraction was carried out with the RNeasy plant minisystem (Qiagen, Hilden, Germany). First-strand cDNA synthesis was done with the Superscript II reverse transcriptase (Gibco BRL Life technologies, Gaithersburg, MD, U.S.A.) primed with an oligo-dT(18) primer. All PCR reactions were carried out with the Expand high fidelity PCR system (Roche, Indianapolis, IN, U.S.A.). Sequencing reactions were carried out with the DYEnamic ET terminator cycle sequencing kit (Amersham Pharmacia Biotech, Cleveland, OH, U.S.A.) and the appropriate oligonucleotides. Sequencing reactions were analyzed on an automated ABI PRISM XL377A DNA sequencer (Perkin-Elmer, Norwalk, CT, U.S.A.). At least two independent clones were sequenced for each construct and fragment analyzed. The sequences of primers and other oligonucleotides used in this study can be obtained from authors by request. 


\section{Viral constructs.}

Viral constructs were generated using the full-length infectious cDNA of PVA-B11 placed under the T7 promoter (Puurand et al. 1996). The $6 \times$ His insertions (constructs p6K2A to p6K2E) (Fig. 1B) and deletions (p6K2 $\Delta 1$ to p6K2 $\Delta 4$ ) (Fig. 1D) were made in the $6 \mathrm{~K} 2$-encoding region with the ExSite PCR-based site-directed mutagenesis kit (Stratagene, La Jolla, CA, U.S.A.), as described (Rajamäki and Valkonen 1999). Insertion and deletion clones were verified by sequencing and transferred into the PVA-B11 cDNA using unique SwaI and ApaI sites. Construct p6K2G $\rightarrow$ C (Fig. 1C) was done by sitedirected mutagenesis to substitute Gly 2 for Cys 2 and to generate a unique $B s p 1407 \mathrm{I}$ restriction site.

Constructs p6K2A1 (Fig. 1B) and p6K2 $\Delta 4 \mathrm{HCT}-1$ were prepared by cloning the 1,208-nt viral fragment flanked by the SwaI and ApaI restriction sites (Fig. 1A) by RT-PCR from total RNA extracted from $N$. benthamiana leaves systemically infected with the spontaneously mutated virus following inoculation with construct p6K2A (discussed above) and 6K2 $\triangle 4 \mathrm{HCT}$ (Fig. 5C). Subsequently, the amplified 1,208-nt fragment was digested with $S w a \mathrm{I}$ and $A p a \mathrm{I}$ and was cloned into the PVAB11 cDNA to replace the corresponding fragment. The whole fragment and the sites of ligation were verified by sequencing.

\section{In vitro transcription and inoculation.}

For the generation of full-length RNA transcripts, $10 \mu \mathrm{g}$ of plasmid DNA was linearized with AgeI, was phenol-chlorophorm extracted, and was resuspended in $10 \mu \mathrm{l}$ of nucleasefree water. Transcription reactions were carried out using the RiboMAX large scale RNA production system (Promega, Madison, WI, U.S.A.) and $\mathrm{m}^{7} \mathrm{GpppG}$ (Promega) for capping, as recommended by the manufacturer. Transcription reaction $(100 \mu \mathrm{l})$ was diluted with $300 \mu \mathrm{l}$ of GKP inoculation buffer (50 mM glycine, $30 \mathrm{mM} \mathrm{K} \mathrm{HPO}_{4}$, $3 \%$ celite, $3 \%$ benthonite), and $25 \mu \mathrm{l}$ of the diluted solution was rubbed onto two fullgrown leaves of 6-week-old $N$. tabacum or $N$. benthamiana seedlings. Plants were grown in an insect-proof greenhouse at 18 and $24^{\circ} \mathrm{C}$ (day and night) under natural daylight supplemented by illumination with fluorescent lamps to extend the day length to $16 \mathrm{~h}$ during winter. Plants were watered daily and fertilized weekly with $0.5 \% \mathrm{~N}: \mathrm{P}: \mathrm{K}=5: 7: 6$ fertilizer.

\section{Virus detection.}

Leaves were tested for PVA by DAS-ELISA as previously described (Rajamäki et al. 1998). Plant tissue was weighed and ground at $1 \mathrm{~g}$ per $3 \mathrm{ml}$ of ELISA extraction buffer, and aliquots were transferred to two wells of an ELISA microtiter plate previously coated with a monoclonal antibody to PVA (MAb 58/0; Agden, Ayr, U.K.). Known amounts of purified virions of PVA-B11 were included for comparison. Detection was carried out with an alkaline phosphatase-conjugated MAb to PVA (MAb 58/0; Agden). Absorbance values were recorded at 405 nm with a Benchmark plate reader (Bio-Rad Laboratories, Hercules, CA, U.S.A.). Different amounts of purified virions were used for comparison to estimate the viral concentrations.

Virus detection by RT-PCR was carried out using primer combinations Swa-F/Apa-R, 6xHis-F/Apa-R, and 6Del1F/Apa-R, as described in Figure 2.

\section{Protoplast preparation, inoculation, and analysis.}

In vitro transcription reactions were carried out as described above. Transcription reactions were DNase treated (1 U per $\mu \mathrm{g}$ of DNA template) at $37^{\circ} \mathrm{C}$ for $2 \mathrm{~h}$, phenol-chloroformextracted, ethanol-precipitated, and resuspended to a final concentration of $1 \mu \mathrm{g} / \mu \mathrm{l}$. Protoplasts from $N$. tabacum and $N$. benthamiana plants were prepared as described by Rao and associates (1994). Protoplasts $\left(1 \times 10^{6}\right)$ were resuspended in $400 \mu \mathrm{l}$ of electroporation buffer $(0.3 \mathrm{M}$ mannitol, $70 \mathrm{mM} \mathrm{KCl,} 5 \mathrm{mM}$ MES, pH 5.8) and were electroporated with $10 \mu \mathrm{g}$ of viral RNA transcripts, using a BioRad Gene Pulser II (capacitance $250 \mu \mathrm{F}$, voltage $250 \mathrm{~V}$ ). After electroporation, protoplasts were resuspended in $6 \mathrm{ml}$ of culture media $(0.55 \mathrm{M}$ mannitol, $10 \mathrm{mM}$ $\mathrm{CaCl}_{2}, \mathrm{pH}$ 5.8) and were incubated in the dark at $24^{\circ} \mathrm{C}$ for $24 \mathrm{~h}$.

Total RNA from protoplast was extracted using the Trizol reagent (Invitrogen, Carlsbad, CA, U.S.A.). RNA concentration was measured at $260 \mathrm{~nm}$, using a GeneQuant II spectrophotometer (Amersham Pharmacia Biotech), and RNA quality was verified by agarose gel electrophoresis. For dot blot analysis, $5 \mu \mathrm{g}$ of total RNA was dotted on a nylon membrane (Hybond-N) (Amersham Biosciences AB, Buckinghamshire, U.K.). Detection of viral positive- and negative-strand RNA was carried out with digoxigenin (DIG)-labeled RNA probes generated using the DIG RNA labeling system (Roche Diagnostics GmbH, Penzberg, Germany), as recommended by the manufacturer.

\section{ACKNOWLEDGMENTS}

We are grateful to M. Mohan for the assistance in protoplast preparations and to M. L. Rajamäki, J. F. Kreuze, and A. Germundsson for helpful comments on the manuscript. Financial support from Formas (grant $301.0663 / 00)$ is gratefully acknowledged.

\section{LITERATURE CITED}

Atreya, C. D., Atreya, P. L., Thornbury, D. W., and Pirone, T. P. 1992. Site-directed mutations in the potyvirus HC-PRO gene affect helper component activity, virus accumulation, and symptom expression in infected tobacco plants. Virology 191:106-111.

Bartels, R. 1971. Potato virus In: Description of Plant Viruses. Commonwealth Mycological Institute and Association of Applied Biologists, Kew, U.K.

Carrington, J. C., Jensen, P. E., and Schaad, M. C. 1998. Genetic evidence for an essential role for potyvirus CI protein in cell-to-cell movement. Plant J. 14:393-400.

Chu, M., Lopez-Moya, J. J., Llave-Correas, C., and Pirone, T. P. 1997. Two separate regions in the genome of the tobacco etch virus contain determinants of the wilting response of tabasco pepper. Mol. PlantMicrobe Interact. 10:472-480.

Culver, J. N. 2002. Tobacco mosaic virus assembly and disassembly: Determinants in pathogenicity and resistance. Annu. Rev. Phytopathol. 40:287-308.

Johansen, I. E., Dougherty, W. G., Keller, K. E. Wang, D., and Hampton, R. O. 1996. Multiple viral determinants affect seed transmission of pea seedborne mosaic virus in Pisum sativum. J. Gen. Virol. 77:3149-3154.

Kekarainen, T., Merits, A., Oruetxebarria, I., Rajamäki, M. L., and Valkonen, J. P. T. 1999. Comparison of the complete sequences of five different isolates of Potato virus A (PVA), genus Potyvirus. Arch. Virol. 144:2355-2366.

Kekarainen, T., Savilahti, H., and Valkonen, J. P. T. 2002. Functional genomics on Potato virus A: A virus genome-wide map of sites essential for virus propagation. Genome Res. 12:584-594.

Laín, S., Riechmann, J.L., and García, J.A. 1990. RNA helicase: A novel activity associated with a protein encoded by a positive strand RNA virus. Nucleic Acids Res. 18:7003-7006.

Li, X. H., Valdez, P., Olvera, R. E., and Carrington, J. C. 1997. Functions of the tobacco etch virus RNA polymerase (NIb): Subcellular transport and protein-protein interaction with $\mathrm{VPg} /$ proteinase (NIa). J. Virol. 71:1598-1607.

Merits, A., Rajamäki, M.-L., Lindholm, P., Runeberg-Roos, P., Kekarainen, T., Puustinen, P., Mäkeläinen, K., Valkonen, J. P. T., and Saarma, M. 2002. Proteolytic processing of potyviral proteins and polyprotein processing intermediates in insect and plant cells. J. Gen. Virol. 83. 1211-1221.

Naderi, M., and Berger, P. H. 1997. Effects of chloroplast targeted potato virus $\mathrm{Y}$ coat protein on transgenic plants. Physiol. Mol. Plant Pathol. 50:67-83.

Puurand, Ü., Valkonen, J. P. T., Mäkinen, K., Rabenstein, F., and Saarma, M. 1996. Infectious in vitro transcript from cloned cDNA of the potato A potyvirus. Virus Res. 40:135-140.

Rajamäki, M. L., and Valkonen, J. P. T. 1999. The $6 \mathrm{~K} 2$ protein and the VPg of Potato virus A are determinants of systemic infection in Nican- 
dra physaloides. Mol. Plant-Microbe Interact. 12:1074-1081.

Rajamäki, M., Merits, A., Rabenstein, F., Andrejeva, J., Paulin, L., Kekarainen, T., Kreuze, J. F., Foster, R. L. S., and Valkonen, J. P. T. 1998. Biological, serological, and molecular differences among isolates of potato A potyvirus. Phytopathology 88:311-321.

Rao, A. L. N., Duggal, R., Lahser, F. C., and Hall, T. C. 1994. Analysis of RNA replication in plant viruses. Pages 216-236 in: Methods in Molecular Genetics: Molecular Virology. K. W. Adolph, ed. Academic Press, Inc., Orlando, FL, U.S.A.

Restrepo-Hartwig, M. A., and Carrington, J. C. 1994. The tobacco etch potyvirus 6-kilodalton protein is membrane associated and involved in viral replication. J. Virol. 68:2388-2397.

Riechmann, J. L., Laín, S., and García, J. A. 1992. Highlights and prospects of potyvirus molecular biology. J. Gen. Virol.73:1-16.

Rodriguez-Cerezo, E., Klein, P. G., and Shaw, J. G. 1991. A determinant of disease symptoms severity is located in the 3'-terminal noncoding region of the RNA of a plant virus. Proc. Natl. Acad. Sci. U.S.A. 88:9863-9867.

Sáenz, P., Cervera, M. T., Dallot, S., Quiot, L., Quiot, J.-B., Riechmann, J. L., and García, J. A. 2000. Identification of a pathogenicity determinan of Plum pox virus in the sequence encoding the C-terminal region of protein P3+6K1. J. Gen. Virol. 81:557-566.

Schaad, M. C., Jensen, P. E., and Carrington, J. C. 1997. Formation of plant RNA virus replication complexes on membranes: Role of an endoplasmic reticulum-targeted viral protein. EMBO (Eur. Mol. Biol. Organ.) J. 16:4049-4059

Schaad, M. C., Haldeman-Cahill, R., Cronin, S., and Carrington, J. C.
1996. Analysis of the VPg-proteinase (NIa) encoded by tobacco etch potyvirus: Effects on mutations on subcellular transport, proteolytic processing, and genome amplification. J. Virol. 70:7039-7048.

Shukla, D. D., Ward, C. W., and Brunt, A. A. 1994. The Potyviridae. CAB International, Wallingford, U.K.

Simón-Buela, L., Guo, H. S., and García, J. A. 1997. Long sequences in the $5^{\prime}$ noncoding region of plum pox virus are not necessary for viral infectivity but contribute to viral competitiveness and pathogenesis. Virology 233:157-162.

Staehelin, L. A. 1997. The plant ER: A dynamic organelle composed of a large number of discrete functional domains. Plant J. 11:1151-1165.

Ullah, Z., and Grumet, R. 2002. Localization of Zucchini yellow mosaic virus to the veinal regions and role of the viral coat protein in veinal cholorisis conditioned by the zym potyvirus resistance locus in cucumber. Physiol. Mol. Plant Pathol. 60:79-89.

Valkonen, J. P. T., Puurand, Ü., Slack, S. A., Mäkinen, K., and Saarma, M. 1995. Three strain groups of potato A potyvirus based on hypersensitive responses in potato, serological properties, and coat protein sequences. Plant Dis. 79:748-753.

Vilar, M., Sauri, A., Monné, M., Marcos, J. F., von Heijne, G., Pérez-Payá, E., and Mingarro, I. 2002. Insertion and topology of a plant viral movement protein in the endoplasmic reticulum membrane. J. Biol. Chem. 277:23447-23452.

Waigmann, E., Che, M.-H., Bachmaier, R., Ghoshroy, S., and Citovsky, V. 2000 Regulation of plasmodesmatal transport by phosphorylation of tobacco mosaic virus cell-to-cell movement protein. EMBO (Eur. Mol. Biol. Organ.) J. 19:4875-4884 